\title{
Demonstração de um dispositivo IoT de monitoramento e multimídia para simuladores de caminhada indoor
}

\author{
Victor T. Hayashi ${ }^{1}$, Fabio H. Hayashi ${ }^{2}$ \\ ${ }^{1}$ Departamento de Engenharia de Computação e Sistemas Digitais \\ Universidade de São Paulo (USP) - São Paulo, SP - Brasil \\ ${ }^{2}$ Laboratórios Didáticos Secos - Universidade Federal do ABC (UFABC) \\ Santo André, SP - Brasil \\ victor.hayashi@usp.br, fabio.hayashi@ufabc.edu.br
}

\begin{abstract}
This paper aims to describe an IoT device that presents the collected data from an indoor walking simulator in a web dashboard in an autonomous and privative way (i.e., with no need for Internet connection and with data collection autonomy of 10 users for 30 days), and it is integrated with multimedia functionalities: video and radio streaming.
\end{abstract}

Resumo. Este artigo descreve um dispositivo IoT que apresenta os dados coletados de um simulador de caminhada indoor em um dashboard web de forma autônoma e privativa (i.e., sem necessidade de conexão Internet e com autonomia de coleta de dados de 10 usuários durante 30 dias), e é integrado a funcionalidades multimídia: streaming de vídeo e rádio.

\section{Introdução}

O sedentarismo é um dos males da sociedade moderna, e que pode contribuir para doenças como hipertensão, depressão e diabetes [SANTA CASA 2021]. Uma pesquisa mostrou que pessoas que não se exercitam tem um risco duas vezes maior de sofrer de doenças do coração, desenvolver diabetes e ter pressão alta [HCOR 2021]. Mesmo que algumas inovações tecnológicas possam contribuir para o sedentarismo [SANTA CASA 2021], outras podem motivar as pessoas a se exercitarem mais, como a solução proposta, que usa a Internet das Coisas (IoT) [ZOU et al. 2020]. O presente trabalho foi desenvolvido durante o período de isolamento físico imposto pela COVID-19 para motivar 4 pessoas a se exercitarem em sua residência em um simulador de caminhada.

\section{Objetivo}

Apresentar o dispositivo IoT de monitoramento e multimídia para motivar o uso de um simulador de caminhada instalado em um ambiente residencial.

\section{Desenvolvimento}

O dispositivo construído com um ESP8266 e uma fonte de alimentação monitora o sensor magnético reed-switch do simulador de caminhada, armazena os dados internamente (com autonomia de 30 dias para 10 usuários) e os disponibiliza a interfaces conectadas na mesma rede WiFi local, atuando como um servidor web. As interfaces desenvolvidas com HTML/CSS/javascript para tablet e celular estão apresentadas na Figura 1. 


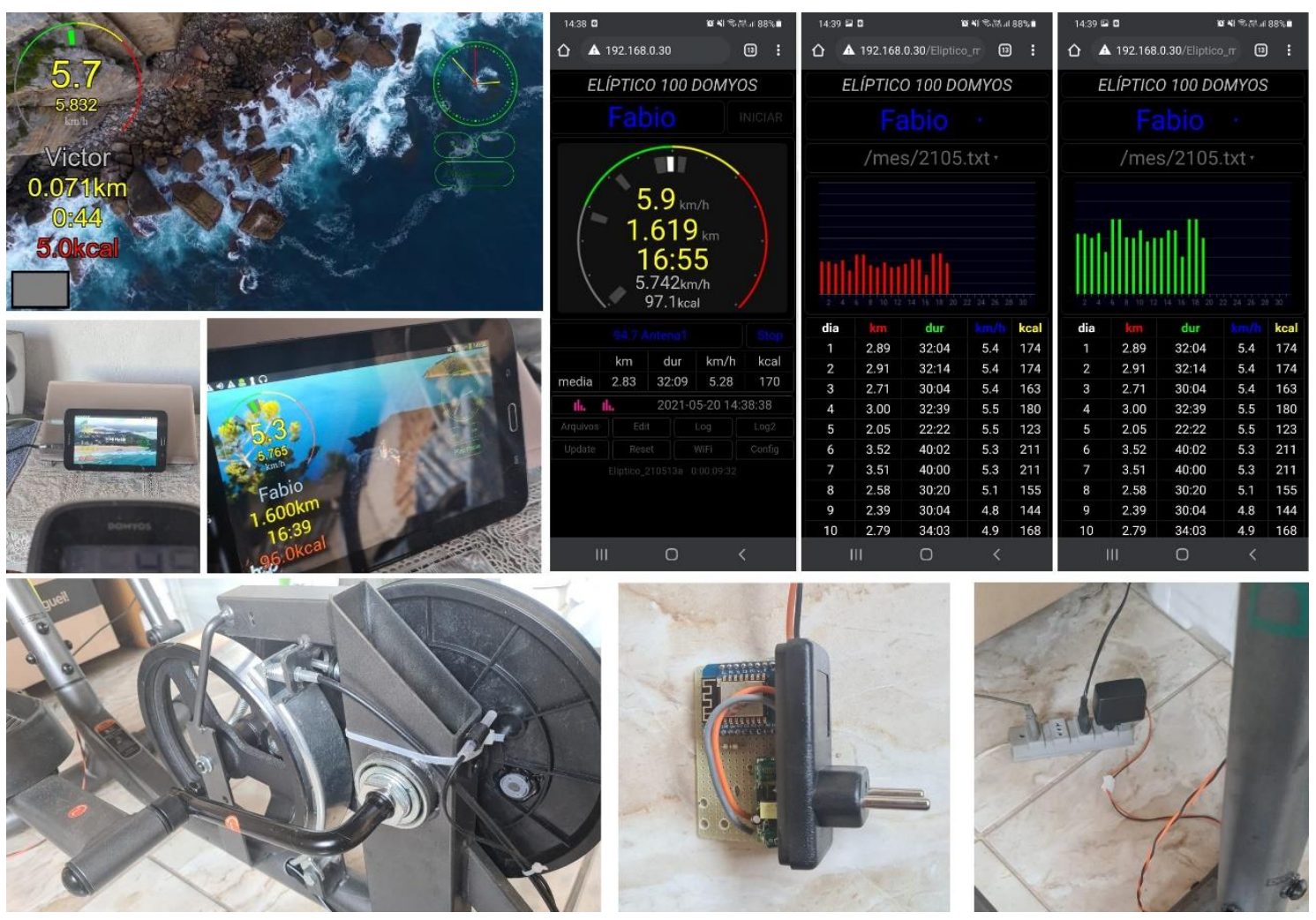

Figura 1. Protótipo do dispositivo loT para simulador de caminhada indoor.

\section{Demonstração}

1. Na tela inicial, o usuário seleciona seu identificador e clica em "INICIAR";

2. Nesta tela inicial, o usuário pode iniciar um streaming de uma rádio online;

3. Se estiver no tablet, o usuário pode clicar no velocímetro no centro da tela, selecionar um vídeo de sua lista de reprodução e executá-la;

4. O usuário pode executar o exercício enquanto assiste ao vídeo ou escuta a rádio online;

5. Ao finalizar, o dispositivo registra automaticamente os dados;

6. Se o usuário desejar verificar como está sua evolução ao longo dos dias, ao clicar nos ícones de gráfico na tela inicial é possível visualizar a evolução da distância percorrida, da duração da caminhada, e uma estimativa de gasto calórico a partir de dados de peso de cada usuário.

\section{Referências}

SANTA CASA (São Paulo). Sedentarismo cresce e preocupa especialistas.

Disponível em: https://www.santacasasp.org.br/portal/site/pub/6292/sedentarismocresce-e-preocupa-especialistas. Acesso em: 20 maio 2021.

HCOR (São Paulo). Estudos revelam que sedentários têm risco dobrado de sofrerem com doenças do coração. Disponível em:

https://www.hcor.com.br/imprensa/noticias/estudos-revelam-que-sedentarios-temrisco-dobrado-de-sofrerem-com-doencas-do-coracao/. Acesso em: 20 maio 2021.

ZOU, Ning; LIANG, Shaobo; HE, Daqing. Issues and challenges of user and data interaction in healthcare-related IoT. Library Hi Tech, 2020. 